\title{
Access to reproductive options after prenatal diagnosis- patient access and physician responsibilities: an updated position statement of the American College of Medical Genetics and Genomics (ACMG)
}

\author{
ACMG Board of Directors ${ }^{1}$
}

\begin{abstract}
Disclaimer: This statement is designed primarily as an educational resource for medical geneticists and other clinicians to help them provide quality medical services. Adherence to this statement is completely voluntary and does not necessarily assure a successful medical outcome. This statement should not be considered inclusive of all proper procedures and tests or exclusive of other procedures and tests that are reasonably directed to obtaining the same results. In determining the propriety of any specific procedure or test, the clinician should apply his or her own professional judgment to the specific clinical circumstances presented by the individual patient or specimen.

Clinicians are encouraged to document the reasons for the use of a particular procedure or test, whether or not it is in conformance with this statement. Clinicians also are advised to take notice of the date this statement was adopted, and to consider other medical and scientific information that becomes available after that date. It also would be prudent to consider whether intellectual property interests may restrict the performance of certain tests and other procedures.
\end{abstract}

Keywords: reproductive options; prenatal diagnosis; access to healthcare
Genetics in Medicine (2020) 22:3; https://doi.org/10.1038/s41436-0190656-1
The American College of Medical Genetics and Genomics (ACMG) is concerned with the enactment of laws in some states that prevent or restrict access to termination of pregnancy after prenatal diagnosis of genetic disorders or congenital anomalies. The practice of medical genetics is predicated on the principle of providing patients with complete and accurate information on the condition that affects them, a member of their family, or an unborn fetus, and then discussing the management options that are available. The ACMG believes strongly that a balanced discussion of reproductive options is required. In some cases, patients will elect to alter the course of their pregnancy or pregnancy care. Patients may decide to investigate adoption or choose to learn about the expected outcome, neonatal care, and long-term care of a child with disabilities. They may also choose termination of pregnancy. Pregnancy termination should be available to pregnant women when their fetus has been diagnosed with a genetic disorder or congenital anomaly. Ideally, this is considered after discussions between the patient's healthcare provider(s) and the pregnant woman or couple with the goal of facilitating their choice of a safe and acceptable management plan. Access to safe and legal termination of pregnancy for genetic disorders or congenital anomalies that are diagnosed prenatally is an important option for some patients, and the ACMG strongly opposes any legislation that places limits on this access.

Further, it is the legal and ethical responsibility of healthcare professionals to provide complete and accurate information including all management options to patients. Laws that criminalize healthcare professionals for informing patients of their options, including termination of pregnancy, are contrary to the sanctity of the doctor-patient relationship and principles of autonomy. Accordingly, ACMG strongly opposes any legislation that prohibits healthcare professionals from providing complete and accurate medical care, or in any manner penalizes the provision of such care.

\section{DISCLOSURE \\ The authors declare no conflicts of interest.}

Publisher's note Springer Nature remains neutral with regard to jurisdictional claims in published maps and institutional affiliations.

\footnotetext{
${ }^{1}$ American College of Medical Genetics and Genomics Board of Directors, Bethesda, MD, USA. Correspondence: ACMG (documents@acmg.net)

The Board of Directors of the American College of Medical Genetics and Genomics approved this statement on 20 April 2018.
} 